\title{
Staged rehabilitation of obstructed right ventricle-to- pulmonary artery conduit with implantation of a Cheatham-Platinum stent mounted on two Tyshak-X balloons followed by a Melody valve
}

\author{
Tomasz Moszura ${ }^{1,2}$, Rafał Surmacz ${ }^{2}$, Sebastian Góreczny ${ }^{1}$, Waldemar Bobkowski², Shakeel Qureshi \\ ${ }^{1}$ Department of Cardiology, Polish Mother's Memorial Hospital, Research Institute, Lodz, Poland \\ 2Department of Paediatric Cardiology and Nephrology, Poznan University of Medical Sciences, Poznan, Poland \\ ${ }^{3}$ Department of Congenital Heart Disease, Evelina London Children's Hospital, London, United Kingdom
}

Adv Interv Cardiol 2017; 13, 2 (48): 182-183

DOI: https://doi.org/10.5114/pwki.2017.68010

A 15-year-old patient, born with pulmonary atresia and intact ventricular septum, having had complete repair and repeat surgical and percutaneous interventions for conduit obstruction, presented with recurrence of a narrowing in the right ventricular outflow tract conduit. Transthoracic echocardiography showed obstruction of the distal part of the conduit with moderate to severe pulmonary regurgitation. Cardiac magnetic resonance imaging revealed additional proximal, bilateral branch pulmonary artery stenosis. Haemodynamic measurements showed right ventricular systolic pressure (69/ $12 \mathrm{~mm} \mathrm{Hg}$ ) to be above $2 / 3$ of the systemic arterial pressure $(90 / 45 / 56 \mathrm{~mm} \mathrm{Hg})$ with normal pulmonary artery pressures (right pulmonary artery - 20/12/15 mm Hg, left pulmonary artery - 29/14/19 mm Hg). Due to complex narrowing at the level of the pulmonary artery bifurcation, a modified technique of stent implantation was used. A bare $34 \mathrm{~mm}$ Cheatham-Platinum stent (NuMED) was manually crimped on two $10 \mathrm{~mm}$ Tyshak-X balloons (NuMED, Figure $1 \mathrm{~A}$ ) and implanted at the distal part of the conduit (Figure $1 \mathrm{~B}$ ). Whilst the intervention resulted in reduction of the right ventricular systolic pressure $(46 / 14 \mathrm{~mm} \mathrm{Hg})$ to less than half the systemic arterial pressure $(95 / 49 / 61 \mathrm{~mm} \mathrm{Hg})$, further redilation (Figure $1 \mathrm{C}$ ) was deferred until the next stage of percutaneous pulmonary valve implantation (Figure $1 \mathrm{D}$ ). The previously implanted stent was redilated with a $20 \mathrm{~mm}$ Mullins $X$ balloon (NUMED) and reinforced with a second Cheatham-Platinum stent delivered on a $20 \mathrm{~mm}$ BiB balloon catheter (NUMED). This was followed by implantation of a Melody valve (Medtronic) on a $20 \mathrm{~mm}$ Ensemble system (Medtronic), resulting in satisfactory final haemodynamic measurements (right ventricle $-37 / 9 \mathrm{~mm} \mathrm{Hg}$, right pulmonary artery - 27/22/24 mm Hg, aorta - 99/43/ $56 \mathrm{~mm} \mathrm{Hg}$ ).

Obstructions within pulmonary artery bifurcation are among the most challenging lesions. Modified stent delivery techniques, staging of the interventions and application of advanced imaging enable good results with reduced risk of complications [1-4].

\section{Conflict of interest}

The authors declare no conflict of interest.

\section{Corresponding author:}

Sebastian Goreczny MD, PhD, Department of Cardiology, Polish Mother's Memorial Hospital, Research Institute, $281 / 289$ Rzgowska St, 93-338 Lodz, Poland, phone: +48 4227121 84, e-mail: sebastiangoreczny@yahoo.pl

Received: 28.09.2016, accepted: 30.12.2016. 

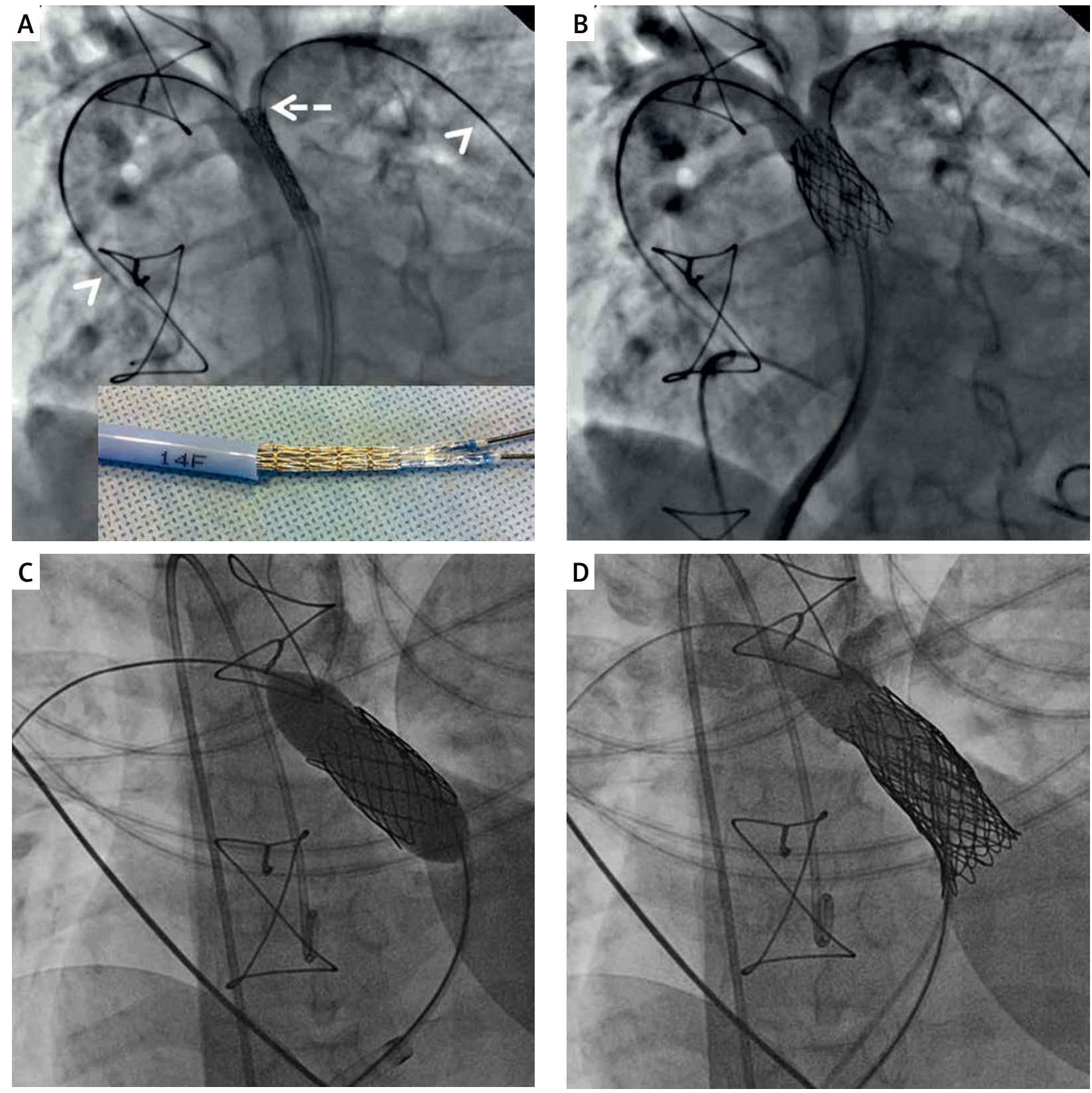

Figure 1. A - After introduction of a $14 \mathrm{Fr}$ long sheath into the conduit, a $34 \mathrm{~mm}$ Cheatham-Platinum stent (NuMED) was mounted on two $10 \mathrm{~mm}$ Tyshak-X balloons (NuMED) and advanced to the level of bifurcation (white dashed arrow) over two extra stiff guidewires (white arrowheads). B - Final angiography shows improved distal conduit obstruction with mild narrowing at the level of bifurcation. C - Six months later a $20 \mathrm{~mm}$ Mullins $X$ balloon (NuMED) was inflated over a wire placed in the right pulmonary artery to simultaneously expand the landing zone and to dilate the proximal pulmonary artery. $\mathrm{D}$ - Final angiography after implantation of a second Cheatham-Platinum stent and the Melody valve (Medtronic Inc.) shows no pulmonary regurgitation with improved proximal right pulmonary artery diameter

\section{References}

1. Stumper O, Bhole V, Anderson B, et al. A novel technique for stenting pulmonary artery and conduit bifurcation stenosis. Catheter Cardiovasc Interv 2011; 78: 419-24.

2. Narayan HK, Glatz AC, Rome JJ. Bifurcating stents in the pulmonary arteries: a novel technique to relieve bilateral branch pulmonary artery obstruction. Catheter Cardiovasc Interv 2015; 86: 714-8.
3. Fiszer R, Dryżek P, Szkutnik M, et al. Immediate and long-term outcomes of percutaneous transcatheter pulmonary valve implantation. Cardiol J 2017 Mar 1. doi: 10.5603/CJ.a2017.0023.

4. Goreczny S, Dryzek P, Moszura T. Novel 3-dimensional image fusion software for live guidance of percutaneous pulmonary valve implantation. Circ Cardiovasc Interv 2016; 9: e003711. 